\title{
EFFECTS OF ESSENTIAL OILS FROM FIVE PLANT SPECIES AGAINST THE GRANARY WEEVILS SITOPHILUS ZEAMAIS AND ACANTHOSCELIDES OBTECTUS (COLEOPTERA)
}

\author{
MAGALIS L. BITTNER ${ }^{a *}$, MARÍA E. CASANUEVA ${ }^{b}$ CECILIA C. ARBERT ${ }^{b}$, MILENKO A. AGUILERA ${ }^{b}$, \\ VICTOR J. HERNÁNDEZ ${ }^{a}$ AND JOSÉ V. BECERRA ${ }^{a}$
}

\begin{abstract}
${ }^{a}$ Departamento de Botánica, Facultad de Ciencias Naturales y Oceanográficas, Universidad de Concepción, Casilla 160-C, Concepción, Chile
${ }^{b}$ Departamento de Zoología, Facultad de Ciencias Naturales y Oceanográficas, Universidad de Concepción, Casilla 160-C Concepción, Chile
\end{abstract} (Received: 22 August 2007 - Accepted: 18 January 2008)

\begin{abstract}
Essential oils obtained from Gomortega keule, Laurelia sempervirens, Origanum vulgare, Eucalyptus globulus, and Thymus vulgaris were analyzed by gas chromatography and gas chromatography-mass spectrometry and evaluated for their toxicity against adults of Sitophilus zeamais (Motschulky) and Acanthoscelides obtectus (Say) (Coleoptera). Contact toxicity was assayed by impregnating filter paper discs with the oils. The amount of essential oils applied in each desiccator (4 1 capacity) was $4,8,16$, or $32 \mu 1$, corresponding to $1,2,4$, or $8 \mu 1 / 1$ air. The results showed significant differences between the tested dosages and exposure periods of the essential oils. Although desirable insecticidal activities against A. obtectus were achieved with the essential oils of all five plants, the oils from $G$. keule and L. sempervirens were the most effective at $96 \mathrm{~h}$. On the other hand, the essential oils of E. globulus and T. vulgaris were most effective against S. zeamais. In all plant species, higher doses or longer exposure periods were more effective against both insects. No mortality was observed in the control group (acetone only) of each species. Therefore, these results suggest that essential oils from the studied plants may be used against insect pests in grain storage.
\end{abstract}

Key words: Biological-activity; Gomortega keule; Laurelia sempervirens; Eucalyptus globulus; Origanum vulgare; Thymus vulgaris; Terpenes toxicity.

\section{INTRODUCTION}

Chemical fumigants such as methyl bromide and phosphine have been used effectively to protect stored food from insect infestations. However, because some stored-product insects have been shown to develop resistance to these chemicals and because of their ozone depletion potential, their use is not recommended at present. ${ }^{1,2}$ Therefore, different developing countries are assaying natural compounds of plant origin as pest control alternatives.

A large number of powders and essential oils from natural products have been used as biological controls against different insect pests since they present no risk to humans and the environment, unlike more conventional pesticides. ${ }^{3-}$ 6 The growth-inhibiting, reproduction retarding, and repellent effects of biological controls have also been demonstrated against storage pests. , $7-10^{2}$

Adults of Sitophilus zeamais (Coleoptera: Curculionidae) and Acanthoscelides obtectus (Coleoptera: Bruchidae) are well-known pests causing economic yield losses in food storage in Chile and many other countries. So far, some attempts have been made to study the effect of medicinal plant powders against $S$. zeamais in stored corn in Chile ${ }^{4}$. Therefore, the aim of the present study was to assess the chemical composition and evaluate the insecticidal effect of essential oils from Gomortega keule, Laurelia sempervirens, Origanum vulgare, Eucalyptus globulus, and Thymus vulgaris plants against S. zeamais and A. obtectus under laboratory conditions.

\section{EXPERIMENTAL}

Insects and rearing conditions: $S$. zeamais and A. obtectus adults were obtained from laboratory cultures maintained on corn and dry beans at $25 \pm$ $1{ }^{\circ} \mathrm{C}, 65 \pm 5 \%$ relative humidity, and under a $12 \mathrm{~h}: 12 \mathrm{~h}$ light:dark regimen. The initial specimens for the laboratory cultures were provided by G. Silva (Agronomy, Chillán, Chile) and L. Parra (Concepción, Chile) and the corn and dry beans were purchased from the local market and maintained in a freezer at $-20{ }^{\circ} \mathrm{C}$ in order to control any arthropod pests prior to use in the cultures. Tests were carried out under similar laboratory conditions.

Extraction of essential oils: The essential oils tested were extracted by hydrodistillation according to Montes et al. and Céspedes ${ }^{11,12}$ from the following plants: Gomortega keule, Laurelia sempervirens, Eucalytus globulus, Origanum vulgare, and Thymus vulgaris. The plants were collected from June-September in 2005 and 2006, in Concepción, Chile. The distilled essential oils were dried over anhydrous $\mathrm{Na}_{2} \mathrm{SO}_{4}$ and stored at $4{ }^{\circ} \mathrm{C}$. Oil composition was analyzed by gas chromatography (GC) and gas chromatography-mass spectrometry (GC-MS). GC analyses of the essential oils were performed using a Gas Chromatograph, Hewlett Packard, series II 5890, using a 30 m HP-5MS (5\%-diphenyl-95\%dimethylsiloxane) capillary column; internal diameter: $0.25 \mathrm{~mm}$, thickness: $0.25 \mu \mathrm{m}$. For the mobile phase, extra pure He (grade 4.5 Indura) was used with a selective mass detector (Hewlett Packard, series I 5972). The relative percentages of the constituents of each essential oil are presented in Table I.

Table 1. Major constituents of essential oils of the different plants analyzed.

\begin{tabular}{|c|c|c|c|c|c|}
\hline \multicolumn{6}{|c|}{ Concentration \% } \\
\hline Constituents & $\begin{array}{c}G . \\
\text { keule }\end{array}$ & $\begin{array}{c}L . \\
\text { sempervirens }\end{array}$ & $\begin{array}{c}\text { E. } \\
\text { globulus }\end{array}$ & $\begin{array}{c}T . \\
\text { vulgaris }\end{array}$ & $\begin{array}{c}O . \\
\text { vulgare }\end{array}$ \\
\hline$\alpha$-Pinene & 7.30 & 0.39 & 9.52 & & 5.12 \\
\hline 1.8 Cineol & 35.57 & & 82.59 & & \\
\hline (+)-3-Carene & 5.17 & 1.97 & 1.79 & 1.54 & \\
\hline $\begin{array}{l}\text { m-Mentha- } \\
\text { 6.8-diene }\end{array}$ & & & 4.72 & & \\
\hline m-Cymene & & & & 3.92 & \\
\hline$\beta$-Pinene & 5.30 & & & & \\
\hline$\alpha$-Terpinene & 7.17 & & & & 5.99 \\
\hline Limonene & 5.40 & & & & \\
\hline p-Cimene & & & & & 4.56 \\
\hline$\gamma$-Terpinene & & & & 25.18 & 13.17 \\
\hline $\begin{array}{l}1 \mathrm{~S} \text { alpha } \\
\text { pinene }\end{array}$ & & & & & 22.14 \\
\hline Thymol & & & & 65.51 & 26.40 \\
\hline $\begin{array}{l}\beta- \\
\text { Felandreno }\end{array}$ & 0.70 & 2.9 & & & \\
\hline Safrol & & 69.30 & & & \\
\hline $\begin{array}{l}\text { 1-methyl- } \\
4-1- \\
\text { methylethyl } \\
\text { ciclohexene }\end{array}$ & & 18.55 & & & \\
\hline $\begin{array}{l}\text { Other } \\
\text { compounds }\end{array}$ & 33.39 & 6.89 & 1.38 & 3.85 & 22.62 \\
\hline
\end{tabular}

Bioassays: To test the toxicity of volatile compounds against adults, desiccators with a 41 capacity were used as test chambers. Twenty adults of Sitophilus zeamais and Acanthoscelides obtectus were added to Petri dishes along with $20 \mathrm{~g}$ of corn and dry bean grains, respectively. The Petri dishes were then placed in the desiccators. The S. zeamais and A. obtectus adults in 
the Petri dishes were exposed separately to the essential oils of Gomortega keule, Laurelia sempervirens, Origanum vulgare, Eucalyptus globulus, and Thymus vulgaris. The tests were carried out under the rearing conditions. Three replicates were done for each combination of dosage and exposure time. The amounts of essential oils applied were $4,8,16$, and $32 \mu 1$ in each desiccator, corresponding to 1, 2, 4, and $8 \mu 1 / 1$ air. Exposure periods were 24, 48, 72, and $96 \mathrm{~h}$. The solvent used for each solution was acetone p.a. 100\%, Merck.

Each dose was applied with an automatic micropipette on a blotting paper strip $(6 \mathrm{~cm} \times 3 \mathrm{~cm})$ attached to the underside of the desiccators. After evaporation $(2 \mathrm{~h})$ of the acetone, the strip was attached to the underside of the desiccators by adhesive tape in order to avoid direct contact with the test material. Final mortality was determined 5 days after exposure. In the control jars, only acetone was applied (maximum dose of $8 \mu \mathrm{l} / \mathrm{l}$ air.

Data analysis: In order to determine if there are statistically significant differences in toxicity among the treatments, a two-way analysis of variance

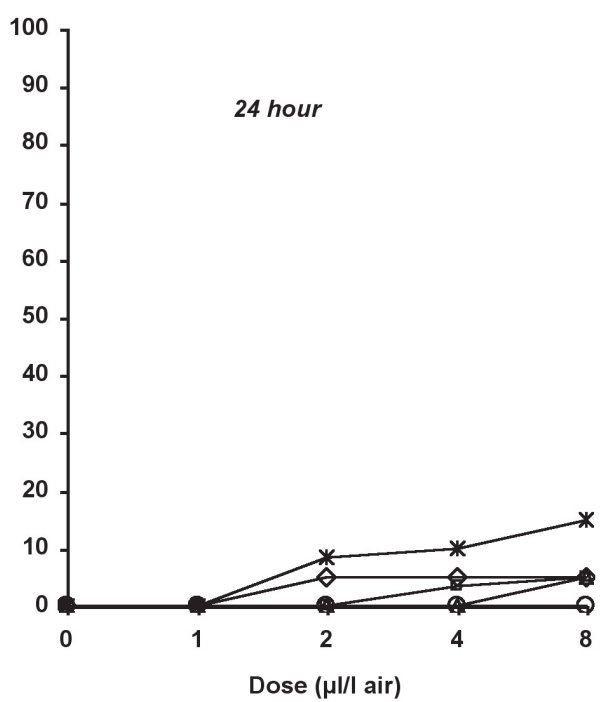

$$
\begin{aligned}
& \rightarrow \text { G. keule } \\
& \leftarrow \text { I. semnervirens } \\
& \rightarrow \text { O. vuloare } \\
& \rightarrow \text { T. vuloaris } \\
& \multimap \text { F. olohulus }
\end{aligned}
$$

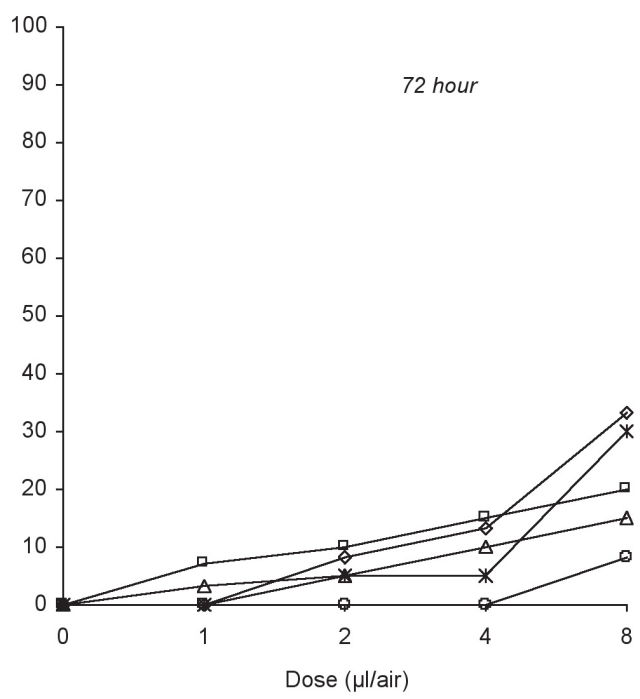

(ANOVA) was carried out using the Statistica 6.0 software package. ${ }^{13}$ The results showed significant differences at $\mathrm{p}<0.01$.

\section{RESULTS}

The qualitative and quantitative compositions of the essential oils of the five plants are presented in Table 1. GC-MS analyses of the oils show only terpenes, mainly monoterpenes. The main constituent of the essential oil from Gomortega keule and Eucalyptus globulus leaves was 1.8 cineol (=Eucalyptol), whereas that of $L$. sempervirens was safrol. On the other hand, the main constituent of $T$. vulgaris and $O$. vulgare was thymol.

All essential oils tested exhibited stronger insecticidal activity against $A$. obtectus adults than against $S$. zeamais adults. Adult mortality increased along with the dosage of essential oils and the exposure period. Percentages of adult mortality in S. zeamais and A. obtectus are shown in Figs. 1 and 2 at different exposure times $(24,48,72,96 \mathrm{~h})$.

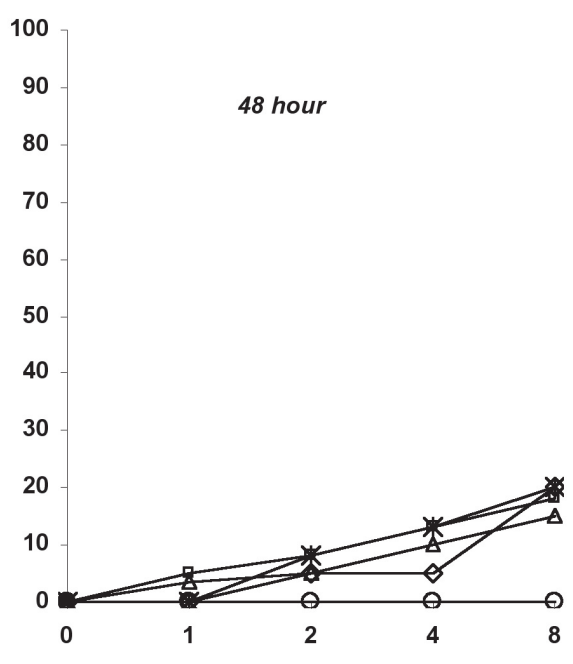

Dose ( $\mu \mathrm{l} / /$ air $)$

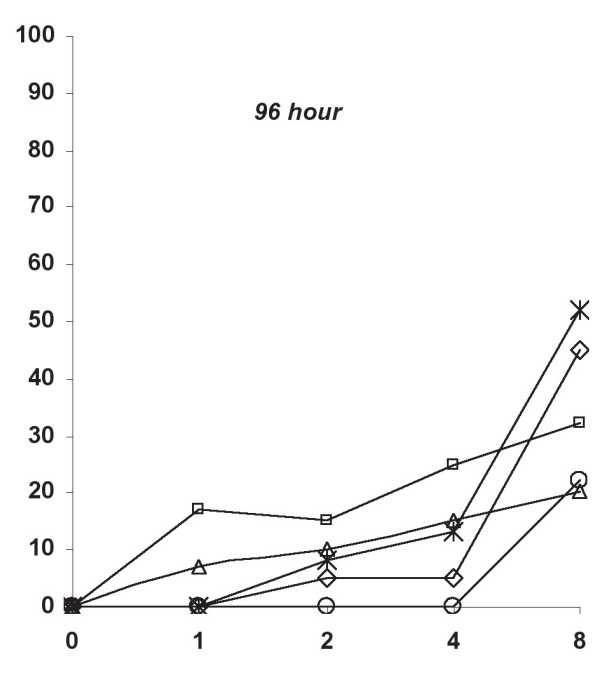

Dose ( $\mu \mathrm{l} / \mathrm{l}$ air)

Fig. 1. Percent of Sitophilus zeamais mortality by dosage and exposure time after treatment with essential oil vapours. 

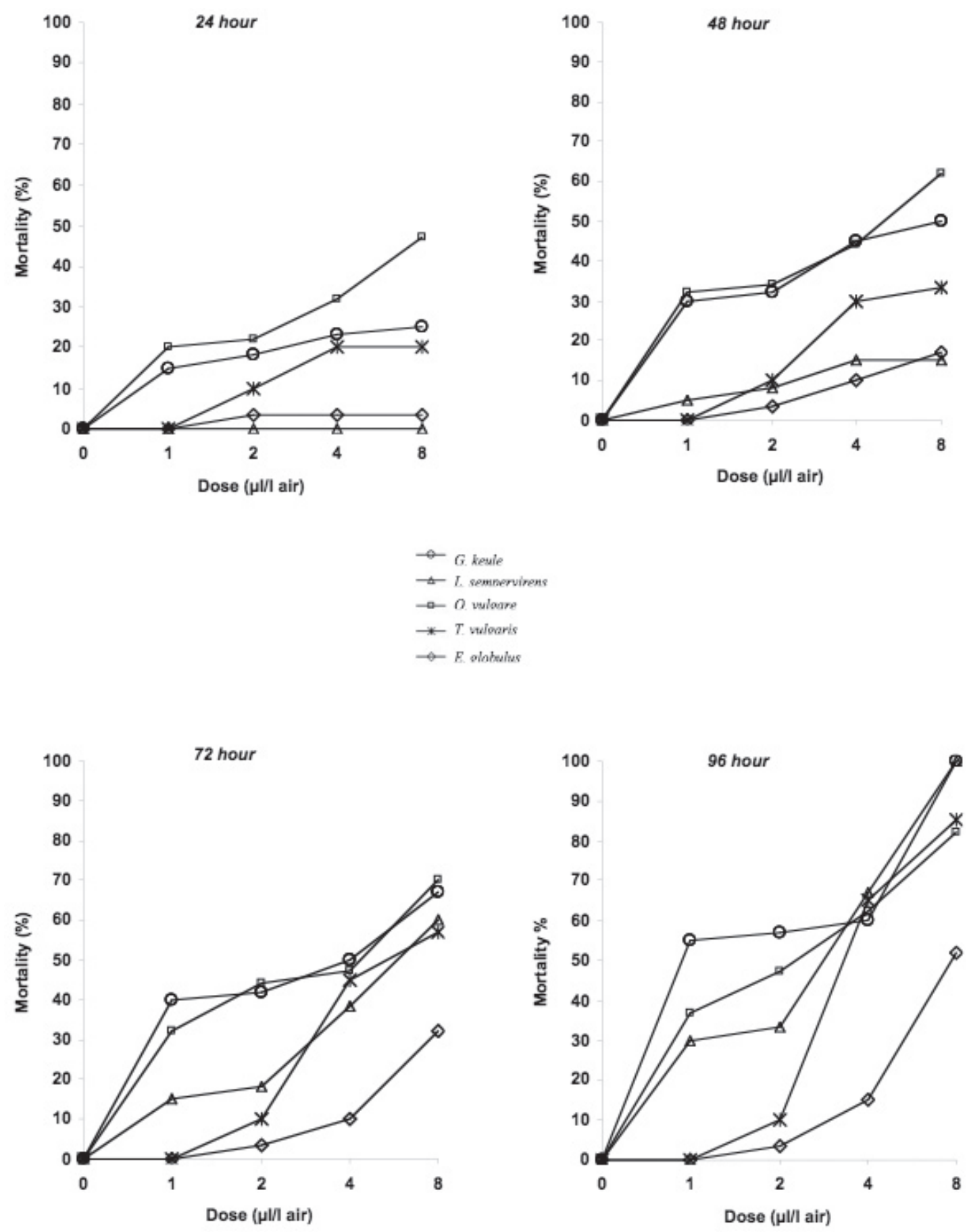

Fig 2. Percent of Acanthoscelides obtectus mortality by dosage and exposure time after treatment with essential oil vapours.

According to the results of the ANOVA, the effects of all the dosages and exposure times of the essential oils were significant at $\mathrm{p}<0.01$ (Tables 2, 3, 4, and 5). Of the five plants tested, the essential oils of T. vulgaris and E. globulus were the most toxic against S. zeamais adults. Mortality was around $55 \%$ for $S$. zeamais when using T. vulgaris $(8 \mu \mathrm{l} / 1$ air at 96 h.; Fig. 1). On the other hand, the essential oils of $G$. keule and L. sempervirens were more effective against A. obtectus, obtaining $100 \%$ mortality with a dose of $8 \mu \mathrm{l} / 1$ air at $96 \mathrm{~h}$ (Fig. 2).

\section{DISCUSSION}

Essential oils obtained from these five plants efficiently killed more adults of $A$. obtectus than of $S$. zeamais. The insecticidal activity increased along with the dosages and exposure times of all the essential oils.

Many plant extracts and essential oils are known to possess ovicidal, repellent, and insecticidal effects against various stored-product insects. ${ }^{2,9,14}$ On the other hand, Ngamo Tinkeu et al (2007) ${ }^{15}$ showed that high doses of essential oils of three aromatic plants (Annona senegalensis, Hyptes spicigera, Lippia rugosa) reduced the ovoposition of $S$. zeamais and concluded that the chronic toxicity prevents grains from destruction. 
Table 2. The results of ANOVA for essential oil dose and exposure time against Sitophilus zeamais.

\begin{tabular}{|c|c|c|c|}
\hline Source & D.F. & Mean square & $\mathrm{F}$ \\
\hline \multicolumn{4}{|l|}{ Gomortega keule } \\
\hline Time (hr) & 3 & 1.039 & $31.167 *$ \\
\hline Dose (uL/L air) & 4 & 2.817 & $84.500 *$ \\
\hline Dose $\mathrm{x}$ Time & 12 & 1.039 & $31.167 *$ \\
\hline Error & 40 & 0.033 & \\
\hline \multicolumn{4}{|c|}{ Laurelia sempervirens } \\
\hline Time (hr) & 3 & 3.689 & $27.667 *$ \\
\hline Dose (uL/L air) & 4 & 1.942 & $14.562 *$ \\
\hline Dose $\mathrm{x}$ Time & 12 & 0.564 & $4.229^{*}$ \\
\hline Error & 40 & 0.133 & \\
\hline \multicolumn{4}{|c|}{ Origanum vulgare } \\
\hline Time (hr) & 3 & 10.639 & $127.667^{*}$ \\
\hline Dose (uL/L air) & 4 & 2.933 & $35.200 *$ \\
\hline Dose $\mathrm{x}$ Time & 12 & 1.333 & $16.000 *$ \\
\hline Error & 40 & 0.083 & \\
\hline \multicolumn{4}{|c|}{ Eucalyptus globulus } \\
\hline Time (hr) & 3 & 2.800 & $8.842 *$ \\
\hline Dose (uL/L air) & 4 & 13.808 & $43.605 *$ \\
\hline Dose $\mathrm{x}$ Time & 12 & 1.453 & $4.588^{*}$ \\
\hline Error & 40 & 0.317 & \\
\hline \multicolumn{4}{|l|}{ Thymus vulgaris } \\
\hline Time (hr) & 3 & 0.150 & 0.136 \\
\hline Dose (uL/L air) & 4 & 11.025 & $10.023 *$ \\
\hline Dose $\mathrm{x}$ Time & 12 & 1.025 & 0.932 \\
\hline Error & 40 & 1.100 & \\
\hline
\end{tabular}

Table 3. The results of ANOVA for essential oil dose and exposure time against Acanthoscelides obtectus.

\begin{tabular}{|c|c|c|c|}
\hline Source & D.F. & Mean square & $\mathrm{F}$ \\
\hline \multicolumn{4}{|l|}{ Gomortega keule } \\
\hline Time (hr) & 3 & 7.661 & 2.471 \\
\hline Dose (uL/L air) & 4 & 38.067 & $12.280^{*}$ \\
\hline Dose x Time & 12 & 2.411 & 0.778 \\
\hline Error & 40 & 3.100 & \\
\hline \multicolumn{4}{|c|}{ Laurelia sempervirens } \\
\hline Time (hr) & 3 & 49.000 & $245.000^{*}$ \\
\hline Dose (uL/L air) & 4 & 44.067 & $220.333 *$ \\
\hline Dose x Time & 12 & 8.278 & $41.389 *$ \\
\hline Error & 40 & 0.200 & \\
\hline \multicolumn{4}{|c|}{ Origanum vulgare } \\
\hline Time (hr) & 3 & 44.417 & $166.563 *$ \\
\hline Dose (uL/L air) & 4 & 28.142 & $105.531 *$ \\
\hline Dose $\mathrm{x}$ Time & 12 & 5.875 & $22.031 *$ \\
\hline Error & 40 & 0.267 & \\
\hline \multicolumn{4}{|c|}{ Eucalyptus globulus } \\
\hline Time (hr) & 3 & 3.600 & $12.000^{*}$ \\
\hline Dose (uL/L air) & 4 & 48.225 & $160.750 *$ \\
\hline Dose $\mathrm{x}$ Time & 12 & 1.725 & $5.750 *$ \\
\hline Error & 40 & 0.300 & \\
\hline \multicolumn{4}{|l|}{ Thymus vulgaris } \\
\hline Time (hr) & 3 & 1.000 & 0.723 \\
\hline Dose (uL/L air) & 4 & 14.442 & $10.440^{*}$ \\
\hline Dose x Tiempo & 12 & 1.542 & 1.114 \\
\hline Error & 40 & 1.383 & \\
\hline
\end{tabular}

Table 4. Results of multiple comparisons with means and S.E. for exposure time and essential oil dose against Sitophilus zeamais.

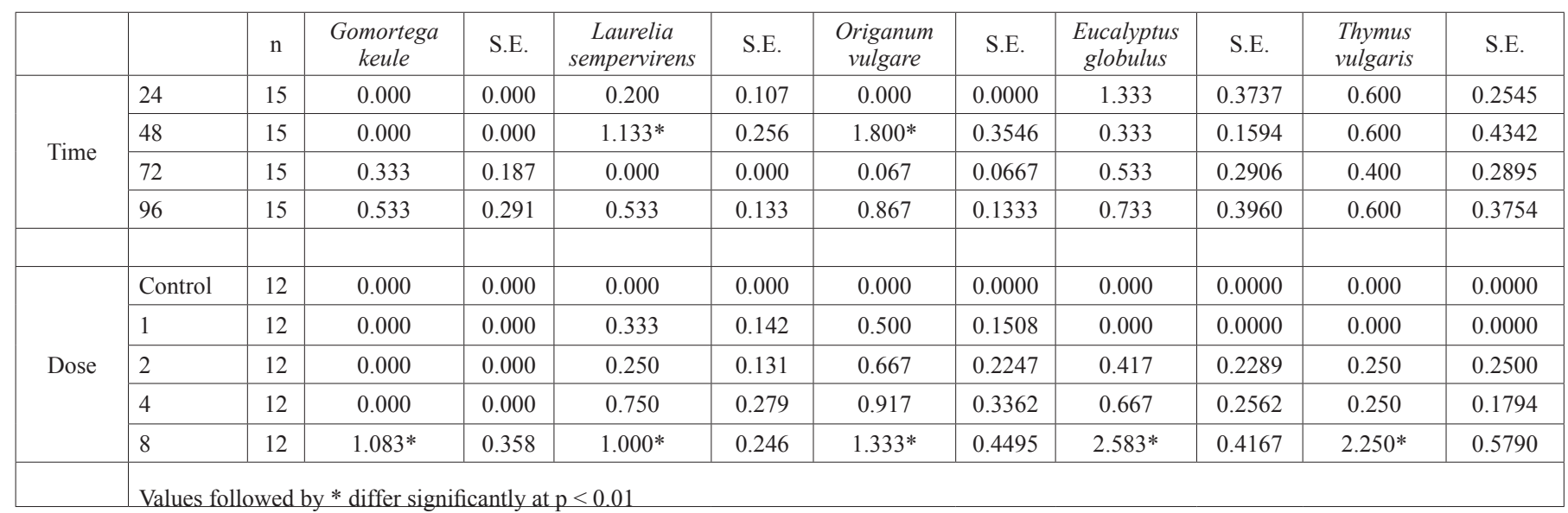


Table 5. Results of multiple comparisons with means and S.E. for exposure time and essential oil dose against Acanthoscelides obtectus.

\begin{tabular}{|c|c|c|c|c|c|c|c|c|c|c|c|c|}
\hline & & $\mathrm{n}$ & $\begin{array}{c}\text { Gomortega } \\
\text { keule }\end{array}$ & S.E. & $\begin{array}{c}\text { Laurelia } \\
\text { sempervirens }\end{array}$ & S.E. & $\begin{array}{c}\text { Origanum } \\
\text { vulgare }\end{array}$ & S.E. & $\begin{array}{l}\text { Eucalyptus } \\
\text { globulus }\end{array}$ & S.E. & $\begin{array}{l}\text { Thymus } \\
\text { vulgaris }\end{array}$ & S.E. \\
\hline \multirow{4}{*}{ Time } & 24 & 15 & 3.267 & 0.5646 & 0.000 & 0.0000 & 0.400 & 0.2138 & 2.000 & 0.5255 & 0.400 & 0.1633 \\
\hline & 48 & 15 & 3.000 & 0.6399 & 1.733 & 0.3305 & $2.600 *$ & 0.5146 & 0.933 & 0.3157 & 0.800 & 0.3928 \\
\hline & 72 & 15 & 1.667 & 0.5578 & $3.533^{*}$ & 0.8387 & $2.600^{*}$ & 0.4000 & 1.533 & 0.5243 & 0.600 & 0.4342 \\
\hline & 96 & 15 & 2.933 & 0.6434 & $3.933^{*}$ & 0.7333 & $3.400 *$ & 0.4957 & 1.933 & 0.6508 & 1.000 & 0.5071 \\
\hline \multirow{4}{*}{ Dose } & 1 & 12 & $2.750^{*}$ & 0.4626 & 1.500 & 0.3371 & $2.083^{*}$ & 0.4167 & 0.000 & 0.0000 & 0.000 & 0.0000 \\
\hline & 2 & 12 & $2.833^{*}$ & 0.2973 & 1.667 & 0.3333 & $2.750^{*}$ & 0.6046 & 0.500 & 0.2887 & 0.167 & 0.1667 \\
\hline & 4 & 12 & $3.000 *$ & 0.6030 & $3.333^{*}$ & 0.6552 & $2.917 *$ & 0.5568 & $3.250 *$ & 0.3509 & 0.750 & 0.2176 \\
\hline & 8 & 12 & $5.000 *$ & 0.8165 & $5.000 *$ & 1.1282 & $3.500^{*}$ & 0.4352 & $4.250 *$ & 0.3509 & $2.583 *$ & 0.7120 \\
\hline
\end{tabular}

The present results showed that the oils of all the plants tested had toxicity against $S$. zeamais and $A$. obtectus. The best results were obtained with the essential oils of $G$. keule and L. sempervirens against $A$. obtectus, and oils of E. globulus and T. vulgaris against S. zeamais. A dose of $8 \mu 1 / 1$ air of $L$. sempervirens or G. keule is required for $100 \%$ mortality at $96 \mathrm{~h}$ for $A$. obtectus. On the other hand, a dose of $8 \mu \mathrm{l} / 1$ air of $T$. vulgaris or E. globulus is needed to kill close to $55 \%$ of $S$. zeamais adults at $96 \mathrm{~h}$.

Previous studies have shown that the toxicity of essential oils obtained from aromatic plants against storage pests is related to the oil's main components ${ }^{16,17}$ such as terpinene, carvacrol, 1.8 cineole, thymol, cymol, eugenol, limonene, a-pinene, among others. The present results agree with those in the literature, since all essential oils tested presented mainly monoterpenes like safrol, 1.8 cineol, terpinene, thymol, and carene.

Papachristos et al. (2004) $)^{18}$ found strong activity against $A$. obtectus with essential oils from lavender and rosemary and minor activity with eucalyptus oil due to the larger proportion of highly active monoterpenoids present in the lavender and rosemary essential oils than in the eucalyptus oil. A similar situation was found in this research, with two native aromatic plants ( $G$. keule and $L$. sempervirens) giving better results against $A$. obtectus.

On the other hand, Obeng - Ofori and Reichmuth ${ }^{19}$ found that essential oils with 1.8 cineol, eugenol, and camphor had the highest toxicity against S. granarius. Although the eucalyptus essential oil tested also presented high concentrations of 1.8 cineol, its toxicity activity against $S$. zeamais was not very effective. This difference could be explained by the fact that the chemical composition of eucalyptus essential oils isolated from different plant parts and collected in different seasons vary qualitatively and quantitatively. ${ }^{18}$

Oil from L. sempervirens presented a high amount of safrol, and oil from G. keule presented eucalyptol. On the other hand, E. globulus presented high concentrations of 1.8 cineol (= eucalyptol). Thymol and gamma terpinene were major components in both $T$. vulgaris and $O$. vulgare. ${ }^{20}$

The present results show that the essential oils from all five plants have the potential to be used in pest control against $S$. zeamais and/or A. obtectus. However, further studies are needed to evaluate the efficacy of these plants on stored-products in commercial stores.

\section{ACKNOWLEDGMENTS}

We would like to thank Gonzalo Silva, Facultad de Agronomía, Universidad de Concepción, Campus Chillán, for providing us with the first specimens of $S$. zeamais. This research was supported by DIUC No. 204.111.039-1.0, Universidad de Concepción, Chile and CONICYT Project ACT-38.

\section{REFERENCES}

1. B. Subramanyam and D. Hagstrum in Integrated Management of Insects in Stored Products. Resistance measurement and management, B. Subramanyam, D. Hagstrum eds. Marcel Dekker, New York, U.S.A, 1995; pp. 331-397

2. E. Yildirim, M. Kesdek, L. Aslan, O. Calmasur, F Sahin, Fresenius Environmental Bulletin, 14 (1): 23-27, (2005)

3. L.A.Tapondjou, C.H. Adler, H. Boud, D.A. Fontem, J. Stored Prod. Res. 38 (4): 395-402, (2002)

4. G. Silva, D.P. Pizarro, P. Casals, M. Berti, Rev. Bras. de Agrociência, 9 (4): 383-388, (2003)

5. L.Aslan, H. Ozbek, S. Kordali, O. Calmasur, A. Cakir, J. Plant Diseases and Protection, 111 (4): 400-407, (2004)

6. T.K. Jayasekara, P.C. Stevenson, D.R. Hall, S.R. Belmain, J. Chem. Ecol. 31 (2): 303-313, (2005)

7. L.B. Tunc, M. Berger, F. Erler, F. Dagli, J. Stored. Prod. Res. 36: 161$168,(2000)$

8. A.K. Tripathi, V. Prajapati, N. Verma, J.R. Bahl, R.P. Bansal, S.P Khanuja S. Kumar, J. Econ. Entom. 95 (1): 183-189, (2002)

9. D.P. Papachristos, D.C. Stamopoulos, J. Stored Prod. Res. 38 (4): $365-$ 373, (2002)

10. B.H. Lee, P.C. Annis, F. Tumaalii, S.E. Lee, Phytoparasitica, 32 (5): 498-506, (2004)

11. M. Montes, L.Valenzuela, T. Wilkomirsky Plantas medicinales, Universidad de Concepción, Concepción, Chile, 1992.

12. C. Céspedes, A. Ulloa, J. Salazar, F. Peric, F. Pardo, J. Agric. Food Chem. 50: 2283-2292, (2002)

13. Statsoft INC Statistica for Windows (Computer Program Manual). http:// www.statsoft.com. 1998

14. G. Silva, A. Lagunes, J. Rodriguez, D. Rodriguez, Agroecología, 66: 4-12, (2002)

15. L.S.Ngamo Tinkeu, A. Goudoum, M.B.Ngassoum, L.G. Mapongmetsen, F. Malaisse, T. Hance, African J. Agr. Research, 2 (4): $164-167$, (2007)

16. B.M. Isman, A.J.Wan, C.M. Passreiter, Fitoterapia, 72: 65-68, (2001)

17. S. Lee, C.J.Petreson, J.R. Coats, J. Stored Prod. Res. 39: 77-85, (2003)

18. D.P. Papachristos, K.I. Karamanoli, D.C. Staopoulos, U. MenkissogluSpiroudi, Pest Management Science, 60: 514-520, (2004)

19. D.C. Obeng-OforI, C. Reichmuth, Intern. J. Pest Management, 45: 155159, (1999)

20. R.P. Adams Identification of essential oils by gas chromatography/mass spectroscopy. Allured Publishing Corporation, Carol Stream, Illinois, USA, 1995. 